\title{
Development of the Simulation \& Experiment System for Martian Atmosphere Simulation Environment Box
}

\author{
Lei Zhang, Gaotong Liu* and Wei Leng \\ Beijing Institute of Spacecraft Environment Engineering, Beijing 100094, China \\ ${ }^{*}$ Corresponding author
}

\begin{abstract}
Study on the characteristics of the Martian atmosphere, selecting the appropriate calculation method, combined with FLUENT fluid finite element calculation software, a simulation of the multiple steady internal flow field of environment box in the Mars atmospheric environment conditions were analyzed. At the same time, the air flow experiment system has been established. The results show that the simulation results are in good agreement with the experimental results. The experimental system and simulation method will provide technical support and reference for the design of the Mars atmosphere simulation box.
\end{abstract} CFD

Keywords—-martian atmosphere; rarefied gas; environment box;

\section{INTRODUCTION}

Mars exploration is the hot spot in the world of deep space exploration. Mars surface environment is characterized by complex and diverse, and the Earth's environment and space environment are very different. The harsh environment will have a significant impact on exploration activities. This requires a simulated surface composite environment to meet the needs of type testing [1].

At present, the research and application of simulation technology in space environment [2-10] is very large. However the simulation and experimental study of the Earth's orbit environment is still inadequate in simulating complex and everchanging environments such as Mars surface temperature, gravel, solar radiation and the atmosphere. In order to meet the requirements of the follow-up Mars exploration model test, it is necessary to carry out Mars ground environment simulation research [6]. In this paper, a simulation method is established. By selecting the process simulation method suitable for the Martian atmosphere and experimenting on the simulation results, it is of great guiding significance to the design of Mars atmospheric simulation environment box.

\section{THEORY FOR THE MARTIAN ATMOSPHERE ENVIRONMENT SIMULATION BOX}

The Martian atmosphere is much thinner than the Earth's atmosphere, and the sparse properties of the Martian atmosphere must be considered in the selection of flow modeling computations, and the Knudsen number [3] is usually used to characterize a meteorological sparsity in lean gas dynamics theory. Knudsen Number of gas molecules mean free path $\lambda$ flow characteristics of the length of the ratio of $L$, especially the expression:

$$
K_{n}=\frac{\lambda}{L}
$$

The average free path of the gas molecules inside the environment box being calculated according to the given temperature and pressure ranges is a maximum of $8.357 \times 10-5$ $\mathrm{m}$, and a minimum of $2.235 \times 10-6 \mathrm{~m}$, with the Knudsen number range of $2.235 \times 10-6 \sim 8.357 \times 10-5$. The flow field inside the environment box belongs to a continuous flow field range, and the N-S equation is applicable in the range of gas conditions under which the environment box is situated.

\section{The Simulation Method For the Martian ATMOSPHERE SIMULATION ENVIRONMENT BOX}

\section{A. Simulation Method}

Lean airflow simulation module is based on Fluent CFD simulation and calculation tools developed for low temperature and low voltage closed-loop fan drive circuit for a variety of environmental chamber program given steady-state or nonsteady-state results, including box pressure, temperature and speed vector distributed.

\section{B. The Boundary Condition}

FLUENT software only adds the same amount of momentum load to the specified area. The corresponding userdefined functions are available through the software's UDF interface. Calculate each cell in the area and apply the corresponding momentum load based on the distance from the center of the cell to the axis of rotation of the fan.

\section{The solution and result output}

The FLUENT solver calculates the flow field based on the Navier-Stokes equations. The law followed by fluid motion is the three laws of conservation of physics, namely the law of conservation of mass, the law of conservation of momentum and the law of conservation of energy. The mathematical descriptions of the fluid laws of these three laws form the basic equations of fluid mechanics. The flow field control equation includes continuous equation, momentum equation and energy equation, and the flow field inside the environmental chamber 
is obtained by solving N-S equation of viscous flow or nonadherent Euler equation. The general form of Navier-Stokes equations and Euler equations is:

$$
\frac{\partial U}{\partial t}+\frac{\partial F}{\partial x}+\frac{\partial G}{\partial y}+\frac{\partial H}{\partial z}=J
$$

Considering $\mathrm{U}, \mathrm{F}, \mathrm{G}, \mathrm{H}$ and $\mathrm{J}$ as vectors, we can represent the Navier-Stokes equation and the Euler equation described above.

\section{Simulation of the Martian ATMOSPHERE SiMULATION ENVIRONMENT BOX}

\section{A. Physical Model and Geometric Model}

The geometric dimensions of the ambient box in the ambient box fig.1. The mixed gas component content shows 95\% carbon dioxide, $3 \%$ nitrogen and $2 \%$ argon.

The simulation model of the environmental box is shown in Fig. 2, taking into account the symmetry of the environmental box to reduce the computational load. The flow field calculation grid of the environmental box is shown in Fig. 3, where the yellow part represents the application area of the momentum source for simulating the ducted fan while the red area represents the test part, which monitors the wind speed of the test part during the calculation.
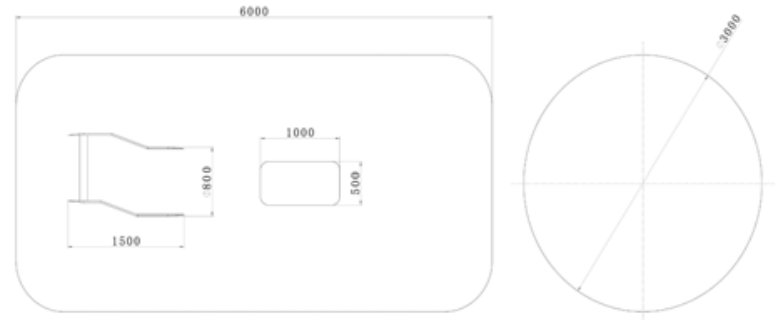

FIGURE I. SIZE OF THE ENVIRONMENT BOX

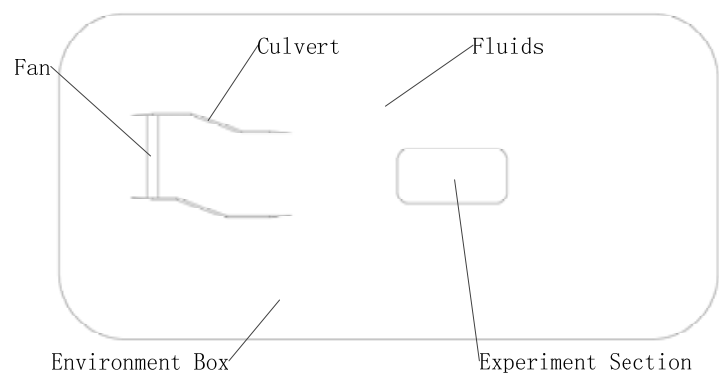

FIGURE II. THE SIMULATION CALCULATION MODEL OF THE ENVIRONMENT BOX

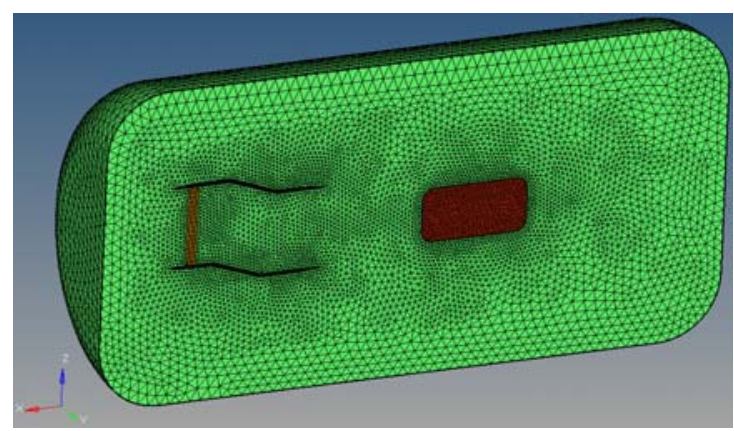

FIGURE III. THE FLUID CALCULATION GRID OF THE ENVIRONMENT BOX

\section{B. Simulation of the Environmental Box}

We have selected $1500 \mathrm{~Pa}$ as the typical operating conditions to simulate the interior flow field of the cylindrical environment box. The environment is $-60{ }^{\circ} \mathrm{C}$, and the speed conditions are $2-16 \mathrm{~m} / \mathrm{s}$.

The velocity vector distribution and the pressure distribution of the cylindrical under typical operating conditions are shown Fig. 4 and Fig. 5. It can be seen from the figure that the test section basically forms a vortex at the edge of the middle laminar flow area at a constant velocity laminar flow area and the air intake of the fan rotor disk is formed near the negative pressure area because of the suction force of the fan, The nip will appear where the fan accelerates air flow to the tank wall due to the fact that the air flow in the zone is retarded and thus increases the pressure and the rest of the pressure, especially the test section, remains at a relatively consistent level.

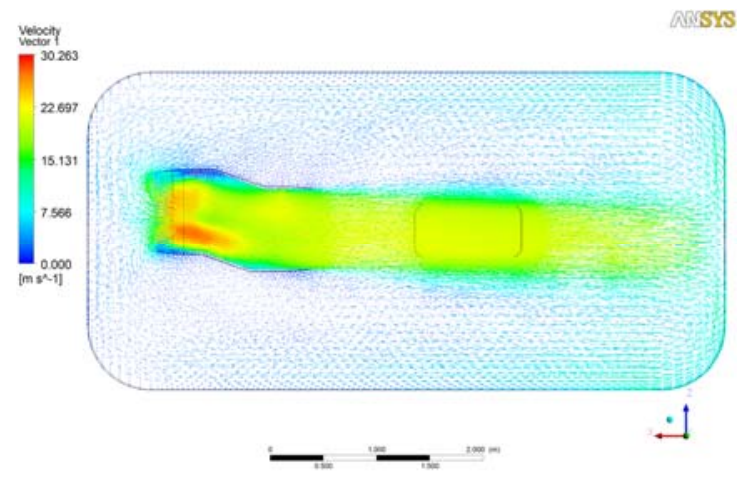

FIGURE IV. THE VELOCITY VECTOR DISTRIBUTION OF THE ENVIRONMENT BOX 


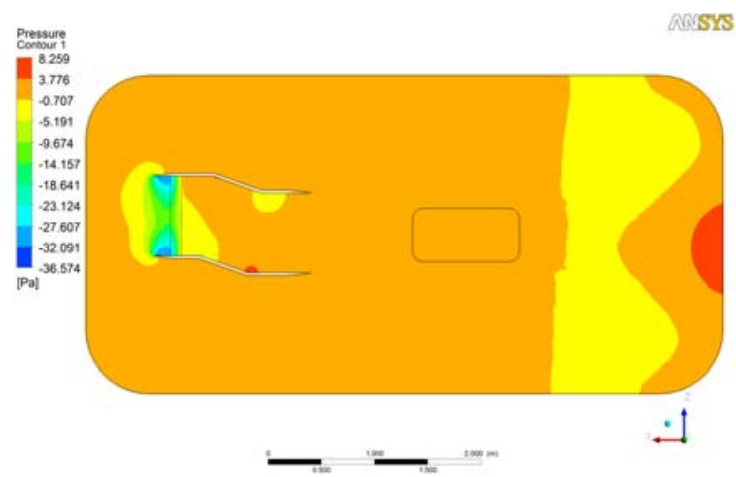

FIGURE V. THE PRESSURE DISTRIBUTION OF THE ENVIRONMENT BOX

Streamline distribution of environmental box shown in Figure 6, from which we can see that the environmental box of the return air flow along the wall of the box mainly cylindrical environment. This reduces the interference of the laminar flow in the test section, which not only improves the stability of the laminar flow in the test section but also reduces the fan power requirement in this case.

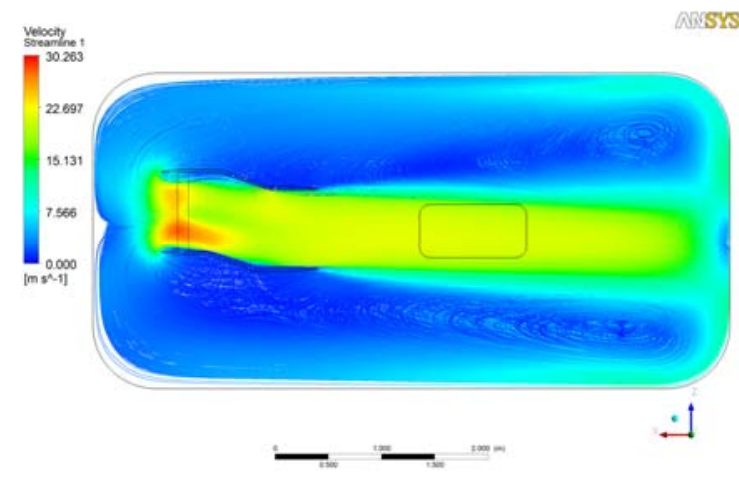

FIGURE VI. THE STREAMLINE DISTRIBUTION OF REFLUX AIRFLOW OF THE ENVIRONMENT BOX

\section{EXPERIMENT AND COMPARISON}

\section{A. Experiment System Development}

According to the low Reynolds number high-efficiency fan design parameters designed by the design software of lowpressure wind speed generator, the processing of the airflow simulation device is completed and the gas flow test system is established to verify the application performance of the wind speed generator at low pressure, as shown in Fig. 7 and Fig.8.

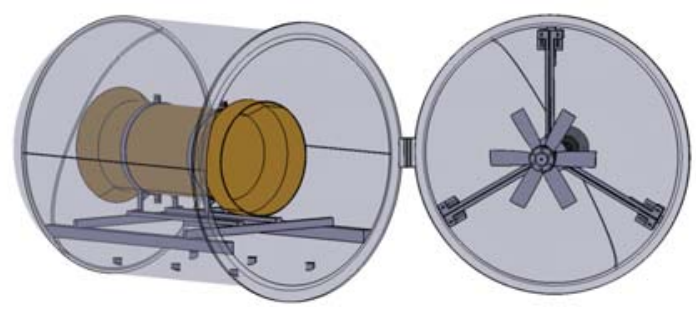

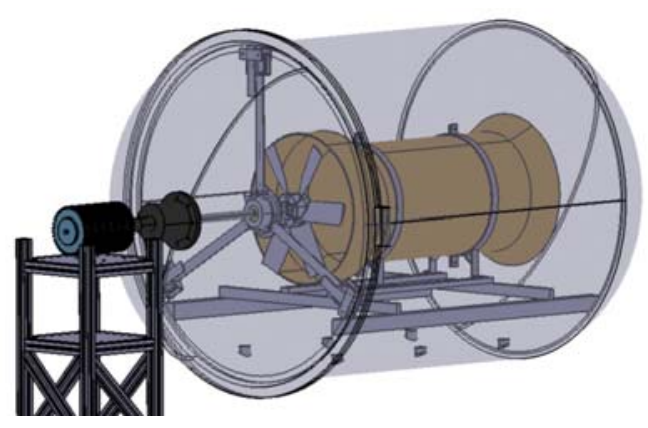

FIGURE VII. THE DESIGN OF THE CYLINDRICAL ENVIRONMENT BOX
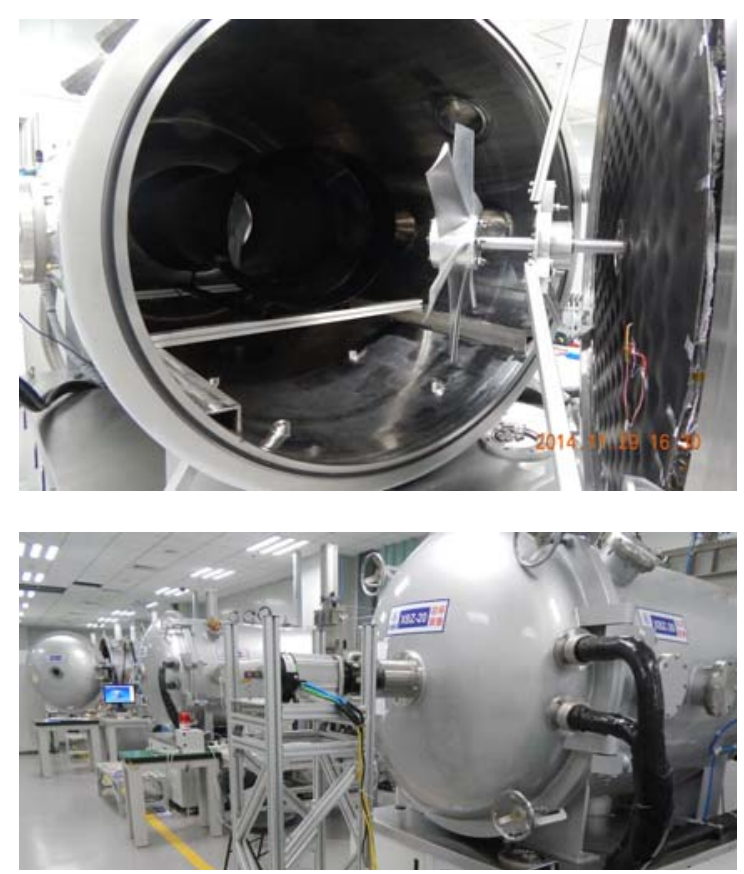

FIGURE VIII. THE DEVICE OF THE CYLINDRICAL ENVIRONMENT BOX

\section{B. Test Result}

The test result of $1500 \mathrm{~Pa}$ was obtained through the test of the low-pressure wind speed generator, and obviously that with the speed of rotor increases, the wind speed also increased accordingly.

Finally, the simulation results are compared with the test results, as in Fig.9. The comparison results show that the simulation results agree well with the experimental results. The results show that the design of low pressure wind speed generator design is reasonable and has certain guiding significance for the design of low pressure fan. 


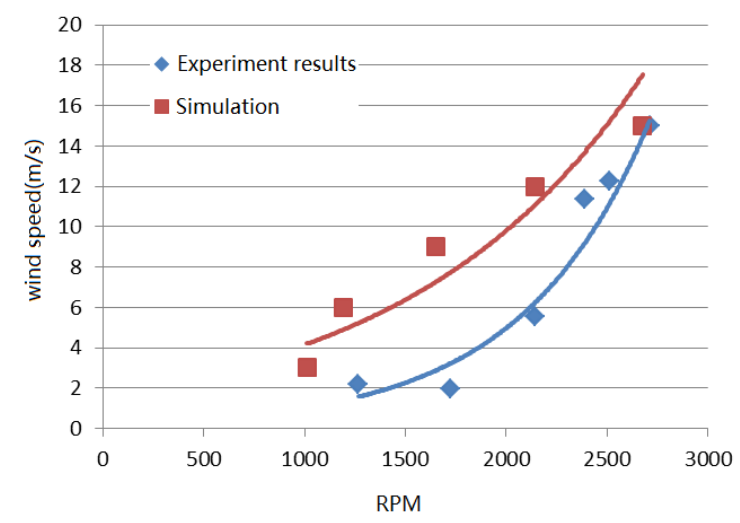

FIGURE IX. COMPARISON OF SIMULATION RESULTS WITH EXPERIMENT RESULTS IN 1500PA AMBIENT PRESSURE

\section{CONCLUSION}

In this paper, the calculation method and calculation model of Mars atmospheric environment box are selected, and the simulation method is established. The simulation was done by using the existing commercial finite element software FLUENT. At the same time, an air flow experiment system was set up, including the development and processing of low Reynolds number high efficient fans, the construction of the platform, the installation of the test device, the final data test and the satisfactory test results. The results show that the simulation results agree well with the experimental results. The establishment of calculation methods and test methods has provided support for the application of Mars atmosphere simulation box in the future.

\section{REFERENCES}

[1] Moss, J. N., Boyles, K. A., and Greene, F. A., "Blunt Body Aerodynamics for Hypersonic Low Density Flows," Proceedings of 25th Symposium on Rarefied Gas Dynamics, edited by Ivanov, M. S. and Rebrov, A. K., Vol. 1, Siberian Branch of the Russian Academy of Sciences, Saint-Petersburg, Russia, 2006, pp. 753-758.

[2] Z. Y. Ouyang, F. G. Xiao. Major scientific issues involved in Mars exploration. Spacecraft Environment Engineering. 2011,28(3):205217 (in chinese).

[3] Votta, R., Ranuzzi, G., Di Clemente, M., Schettino, A., and Marini, M., "Evaluation of Local Effects of Transitional Knudsen Number on Shock Wave Boundary Layer Interactions," 39th AIAA Thermophysics Conference, AIAA Paper 2007-4545, June 2007.

[4] R. D. Braun, R. M. Manning. Mars exploration entry, descent and landing challenges[J]. Journal of Spacraft Rockets, 2007, 44(2):310-323.

[5] Park, C., "A Review of Reaction Rates in High Temperature Air," AIAA

[6] Paper 89-1740, June 1989.

[7] Millikan, R. C., and White, D. R., "Systematic of Vibrational Relaxation," The Journal of Chemical Physics, Vol. 39, No. 12, 1963, pp. 3209-3213.

[8] G. J. LeBeau, K. A. Boyles and F. E. Lumpkin.Virtual Sub-cells For The Direct Simulation Monte Carlo Method.AIAA paper2003-1031,2003.

[9] Park, C., and Lee, S. H., "Validation of Multi-Temperature Nozzle Flow Code NOZNT," AIAA Paper 93-2862, 1993.

[10] R.John Wilson, Mark I. Richardson, The Martian Atmosphere During the Viking Mission, I: Infrared Measurements of Atmospheric Temperatures Revisited, Icarus, Volume 145, Issue 2, 2000, Pages 555579
[11] Borrelli, S., and Pandolfi, M., "An Upwind Formulation for the Numerical Prediction of Non Equilibrium Hypersonic Flows," 12th International Conference on Numerical Methods in Fluid Dynamics, Springer-Verlag, Berlin, 1990, pp. 416-420. 